\title{
Effect of Polyherbal Formulation in Treatment of Poly Cystic Ovarian Syndrome (PCOS)
}

\author{
Dr. Sarang Deshpande ${ }^{1}$, Dr. Kamini Moundekar ${ }^{1}$, Dr. Shailesh Malekar ${ }^{2}$, \\ Patni Showkat ${ }^{2}$, Ujawane Pragati ${ }^{2}$ \\ 1) Ashtang Ayurved Chickitsalaya, Sakkardara, Nagpur (M.S.) \\ 2) Unijules Life Sciences Ltd, Kalmeshwar (M.S.)
}

\begin{abstract}
Poly cystic ovarian syndrome (PCOS) is a complex syndrome affecting 5 to $15 \%$ of the females of reproductive as well as premenopausal age. It involves various symptoms related to metabolism and reproductive system. According to Ayurveda it is a disorder of Artav-vah strotus caused by vitiation of Kapha and Vata.

In this study a Polyherbal formulation prepared by Unijules life Sciences ltd. is evaluated on 36 patients suffering from various symptoms of PCOS for three months treatment duration. A highly significant result was observed in pain during menstruation, interval between two menses, follicular size and in decreasing the BMI i.e. in obesity also.

Overall this study established a good product useful for PCOS without causing any unwanted effects.
\end{abstract}

\section{Introduction:}

Polycystic ovarian syndrome (PCOS) is the most common disorder in women of reproductive age as well as premenopausal women. ${ }^{1}$ This is a type endocrine disorder which involves an ovulation, hirsutism, irregular and painful menstrual cycles, amenorrhea, having small cysts in the ovaries etc. This is a major cause of infertility in women, also known as stein-levithel syndrome. ${ }^{2}$

Clinically, PCOS is made up of three characteristics: hyperandrogenic state, anovulation and insulin resistance ${ }^{(3.4)}$ the accompanying insulin resistance and hyperinsulinemia mark PCOS as a prediabetic state, with high incidence of impaired glucose tolerance, gestational diabetes, and overt diabetes. In patients with PCOS, other metabolic and biochemical changes, such as hypertension and dyslipidemia, increase the risk of cardiovascular disease.

According to Ayurveda PCOS is caused by the imbalance of the three doshas in which aggravated kapha affects the functions of vata and pitta by which ras and rakta dhatu get affected with formation of Ama (toxins) in weaker channels of the body affecting artav-vaha strotus which is responsible for reproduction in female body.

\section{Materials And Methods:}

Enrollment of the Patients: This study was carried out in ASHTANG AYURVEDA Clinic. The patients attaining the OPD and fulfilling the criteria of selection were enrolled in the trial irrespective of their religion, cast etc.

Criteria for Inclusion: Female patients aged between 12 to 65 and fulfilling the ESHRE/ASRM - Rotterndam revised criteria for PCOD, 2003 (fulfilling at least two of the following three criteria) ${ }^{5}$ were enrolled in the study.

1. Oligomenorrhea and/or anovulation

2. Hyperandrogonism (Clinical and/or bio-chemical)

3. PCO-diagnosed by Trans Vaginal Sonography (TVS)

Criteria for Exclusion: Following patients were excluded from the trial

1. Patients having Oligomenorrhea and anovulation due to any other etiology apart from PCOD.

2. Patients having severe chronic diseases like tuberculosis, carcinoma, any illness of reproductive system and/or pelvic disorders etc.

3. Patients having any congenital deformities, cardiac problems etc.

4. Patients of severe insulin resistance, severe thyroid abnormalities, Cushing's syndrome, were excluded.

5. Patients of adrenal hyperplasia, androgen secreting neoplasm were also excluded from the trial.

\section{STUDY DRUG:}

This is a Polyherbal formulation of Unijules Life Sciences Ltd. formulated from the standardized extracts of Sharapunkha (Tephrosia Purpurea), Latakaranja (Cesalpinia cristea), Haridra (Curcuma longa), Shatapushpa 
(Anethum sowa), Shatawari (Asparagus racemosus), Trikatu, and Tankan bhasma (Borax). in a capsule form of $500 \mathrm{mg}$.

\section{STUDY DESIGN:}

This was an open labeled, non comparative study conducted after taking prior informed consent of the patients. Total 44 patients were enrolled in the study out of which 36 patients had completed the 12 week duration of treatment. In this period all patients were advised to take the capsules in a dose of one capsule two times a day after meal. Patients were called up for follow up after every one month.

\section{Assessment criteria:}

During each visit patients were assessed for the duration of menses, size of the follical and ovulation, Body mass index (BMI) and pain during menses. Symptom score from 0 to 3 depending on severity was assessed for all symptoms.

Obtained results were measured according to the grades as completely improved (100\% relief), marked improvement ( 75 to $100 \%$ ), Moderate improvement (50 to $75 \%$ ), mild improvement (25 to $50 \%$ ) and unchanged (upto $25 \%$ ).

During treatment period patients were advised for dietary habits needed for reduction in weight. Avoid junk foods and for some exercise in morning.

\section{INVESTIGATIONS:}

Routine investigations of $\mathrm{Hb} \%$, TLC, DLC, ESR were carried out before and after treatment also USG was done on $2^{\text {nd }}$ and $3^{\text {rd }}$ day of menses for PCO and in between $12^{\text {th }}$ to $20^{\text {th }}$ day of menstruation for follicular growth and ovulation. Also serum analysis for LH and FSH were done on $2^{\text {nd }}$ and $3^{\text {rd }}$ day of menses.

\section{STATISTICAL ANALYSIS:}

All data was analyzed by using appropriate statistical tests by considering $p<0.0001$ as a highly significant, $\mathrm{p}<0.001$ as significant and $\mathrm{p}<0.05$ as insignificant.

\section{Observation And Results:}

In present study most of the patients belongs to the age group 25 to 40 i.e. $61.11 \%$, while $83.33 \%$ females were married and $66.66 \%$ were of vegetarian diet. (Table 1) $60.11 \%$ of the patients were housewife and $65.43 \%$ patients were suffering from irregular menses (Oligomenorrhoea). $85.33 \%$ females were having improper dietary habits (Vishamashan), $35.04 \%$ were having painful menses and $50.76 \%$ cases were of primary infertility. $69.11 \%$ patients were of Vatakaphaj prakruti. More than $70.99 \%$ had stress, $75.43 \%$ had symptoms of Ama and Mandagni. 25.25\% were obese, 85.58\% were having bilateral PCO as per USG report. 90.66\% had follicular size between $0-10 \mathrm{~mm}$ and LH:FSH ratio was $>2$ in $34.22 \%$ of the patients.

After the completion of 3 months treatment period highly significant results were obtained in reducing pain during menstruation $(60.82 \%)$, and in reducing the irregularity of menses i.e. in reducing the interval between two menses $(52.72 \%)$. Whereas significant results were obtained in follicular growth/ovulation $(77 \%)$ and in reducing obesity $(17.72 \%)$.

On overall assessment $27.77 \%$ patients showed complete improvement, $13.88 \%$ showed marked improvement, $41.66 \%$ patients showed moderate improvement, where as $5.55 \%$ of patients showed mild improvement and $11.11 \%$ patients didn't have any improvement in the symptoms of PCOD.

All the hematological parameters were within limits

\begin{tabular}{|l|l|c|l|}
\hline \multicolumn{4}{|c|}{ Table 1 Demographic data of the Patients } \\
\hline & & No. of pt. & \% \\
\hline \multirow{4}{*}{ Age group } & 12 to 25 & 6 & 16.66 \\
\cline { 2 - 4 } & 25 to 40 & 22 & 61.11 \\
\cline { 2 - 4 } & 40 to 55 & 6 & 16.66 \\
\cline { 2 - 4 } & 55 and above & 1 & 2.77 \\
\hline \multirow{3}{*}{ Marriage } & Married & 30 & 83.33 \\
\cline { 2 - 4 } & Unmarried & 6 & 16.66 \\
\hline \multirow{3}{*}{ Diet } & Vegetarian & 24 & 66.66 \\
\cline { 2 - 4 } & Mix & 12 & 33.33 \\
\hline
\end{tabular}


Effect Of Polyherbal Formulation In Treatment Of Poly Cystic Ovarian Syndrome (Pcos)

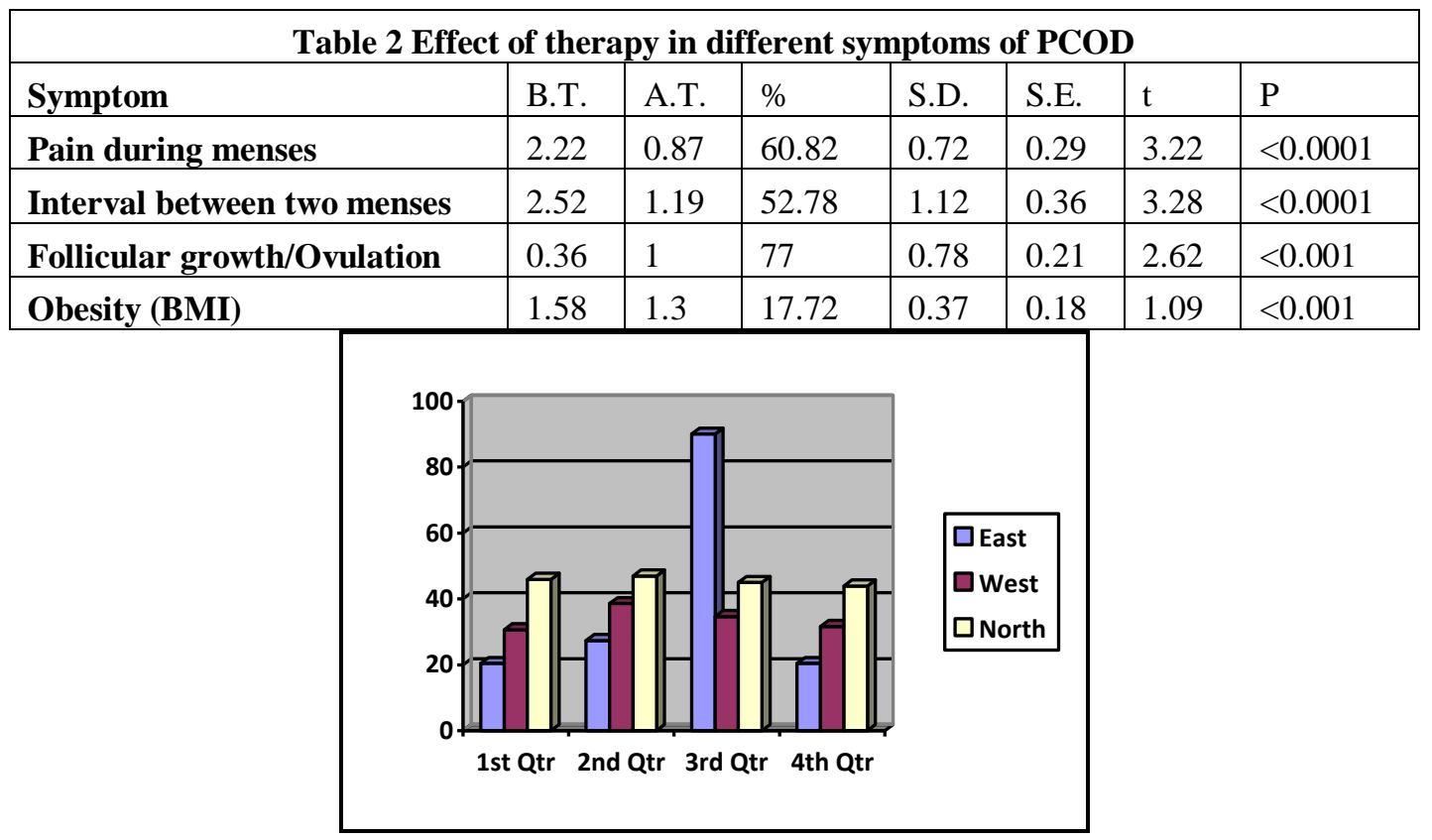

\section{Discussion:}

In PCOD lots of immature eggs are formed in ovaries due to too much production of luteinizing hormone (LH) compared to follicle-stimulating hormone (FSH), but due to too much production of male hormone testosterone their ovulation doesn't occur, which results in formation of cysts with associated disorders related to menstruation.

Most of the times pts with PCOS are treated with hormonal therapies, though it gives relief in short period but the hormones which are secreted naturally or physiologically when supplied by artificial means it puts endocrine system in to sleep and puts body in a lazy mode causing irreversible metabolic damages. So treatment for PCOS should be holistic in context of regulating menstruation by means of curing all associated disorders.

Metformin is widely used drug for treatment of PCOS to reduce the insulin resistant, but these study shows that as we go strictly with the protocol of reducing metabolic disorders we need not to go with metformin which will definitely prevents side effects and cures the disease holistically. This polyherbal formulation is composed in such a way which cleanses, nourishes and rejuvenates entire metabolism along with regulating the female reproductive system.

Sharapunkha (Tephrosia purpuria) is a bitter tonic, mainly used for liver, spleen and kidney disorders. It has anti-inflammatory, cleansing, tonic activities which help in curing several metabolic disorders. Animal studies on wister rats in which PCOS was induced by letrozole treatment showed significant results in relieving the symptoms of PCOS showing normalcy in estrous cycle further to induce ovulation and fertility. ${ }^{6}$ Latakaranja (Caesalpinia crista) is a uterine tonic which helps in proper production and secretion of ovum. It cleanses and nourishes the uterus. It is useful in alleviating vata dosha by which it checks the digestive troubles, amenorrhea and reduces the pain associated with menstruation etc. Haridra (Curcuma longa) is a well known herb having anti-inflammatory and cleansing activity, it helps in alleviating kapha dosha which helps in removing the toxins and opens up the blocked sub channels affecting proper estrous cycle. Shatapushpa (Anethum sowa) is useful in correcting Artava kshaya (oligomenorrhoea) and Kashtartava (dysmenorrhoea) ${ }^{7-8}$. It nourishes the rasa and rakta dhatu which helps in proper metabolism and production of the ova in ovaries. Shatavari (Asparagus racemosus): is the herb having anti-stressor, immunomodulatory and tonic activity for women. It improves overall issues related to reproductive system and fertility. It has the demulcent action which acts as a protector and tonic for the mucous membrane. It has the estrogen modulating activity which contributes to menstrual cycle regulation. Trikatu (Sounth, marich pippali) is cleansing, bio-availability enhancer and corrects the metabolism by removing the toxins. Improves appetite and helps in maintaining the proper lipid profiles. Tankan bhasma is astringent and antiseptic; it promotes the menstruation and uterine activities. It checks amenorrhoea, dysmenorrhoea etc. it alleviates kapha and vata and removes the obstruction in sub channels. Also significant results were observed in anorexia and overall digestion and metabolism of the patients showing that this formulation has overall effect on entire pathophysiology of the disease. 


\section{Conclusion:}

Current study shows significant results in overall symptoms of the PCOS i.e. pain during menses, oligomenorrhoea, follicular size and reduction in PCO, as well as it also helps in reduction of body weight. Means final outcome of the study was very encouraging which will definitely help in treatment protocols of PCOS.

\section{References:}

[1]. Janssen O.E., Mehlmauer N., Hahn S., Offner A.H. and Gartner R., High prevalence of autoimmune thyrodities in patient with polycystic ovary syndrome, European journal of Encyclopedia 150 (2004)

[2]. Fallon L.F., Polycystic Ovary Syndrome, Gale encyclopaedia of medicine, Gale group (2006)

[3]. Wang HS, Wang TH. Polycystic ovary syndrome (PCOS), insulin resistance and insulin-like growth factors (IGfs)/IGF-binding proteins (IGFBPs). Chang Gung Med J 2003;26:540-53.

[4]. Ortega-Gonzalez C, Luna S, Hernandez L, Crespo G, Aguayo P, Arteaga-Troncoso G, Parra A. Responses of serum androgen and insulin resistance to metformin and pioglitazone in obese, insulin-resistant women with polycystic ovary syndrome. J Clin Endocrinol Metab 2005; 90:1360-5.

[5]. Kumar P, Malhotra N. Jeffcoate's Principles of Gynaecology. $7^{\text {th }}$ ed. New Delhi: Jaypee Brothers Medical Publishers; 2008 . pp. 384.

[6]. Prospective use of Tephrosia Purpurea in Remedial Treatment of PCOS:Study in Wistar Rat Patel Anuradha Jitendra1* and Thakor Akanksha Pravin, ISCA Journal of Biological Sciences, Vol. 1(3), 1-6, July (2012).

[7]. Clinical efficacy of Shatapushpa (Anethum sowa Kurz.) powder in the management of Artava kshaya (oligomenorrhoea) A. Ghose and P. K. Panda. International journal of research in Ayurveda, 2010 Oct-Dec; 31(4): 447-450.

[8]. Kashyapa Samhita. 7th ed. Varanasi: Chowkhamba Sanskrit Pratisthana; 1994. Vidyotini Hindi Commentary; p. 184. 